opened by Dr. Naunyn, who said that they exhibited various types in the typical severe attacks as well as in the more chronic irregular forms. Since surgery is increasingly, and with great success, coning to treat these cases, internal medicine should not be backward, and must seek for new methods of cure for these very chronic and insidious forms of disease. The questions as to the origin and formation of the calculi are of fundamental importance for treatment, but have been very variously answered. Some consider their formation due to an excess of cholesterin and bilirubin concretions in the bile, or that the disease depends on the materials being made insoluble through changes in the chemical composition and reaction of the bile. But cholesterin occurs not only in the bile; it is found in the blood, and the bile contains almost a constant quantity ( $2 \frac{1}{2}$ per cent.), without relation to the kind of nutriment, or of the amount in the blood, which often exceeds that in the bile. The amount of lime salts in the bile is also very constant. Chemical changes determining the precipitation of certain constituents of the bile are not proved as indispensable. In the aged there are often but few sym. ptoms, so that during life no diagnosis is made; for whereas among younger persons 5 to 6 per cent., or even 10 to 12 per cent., of all bodies examined contain gall-stones, in aged subjects the nroportion is much higher. According to Schröder, women are affected five times as frequently as men; before thirty they are rare; about 25 per cent. of the cases occur after sixty. Women who have borme children suffer more than others. It is inferred, therefore, that conditions causing stagnation of bile are the cause of the affection, such as pregnancies, tight lacing, \&c. The type of costal respiration in females is a favouring circumstance. The frequency of the affection in the aged points also to stagnation due to atony. Artificial inspissation of bile does not form calculi, nor does the precipitation of insoluble sub. stances; but it is far more probable that they arise exclu. sively from a change in the epithelium of the mucous membrane of the bile ducts. The calculi, at first small and rough, generally possess a central cavity filled with pulpy material or fluid. Bilirubin and lime salts are precipitated, and then cholesterin; and the former may form a sort of shell, within which c onsolidation subsequently takes place. Often the cavity contains clear fluid, and such stones are very friable. Cholesterin is deposited on the surface, and may penetrate into the in terior; often calculi are quite white from cholesterin. These soft stones may harden from deposit of carbonate of lime. The biliary mucous membrane is always affecteddesquamative angiocholitis. The condition of stasis also gives opportunity for the inflamed membrane to become infected with bacilli (one form resembles the bacterium coli commune of Escherich), which may sometimes even penetrate the calculi. The phenomena of the disease may bo divided into regular typical cholelithiasis and irregular atypical forms, the latter often leading to cancer, and therefore of bad prognosis. As to treatment, he remarked that but little was to be expected from so-called solvents as it had been shown that only very small amounts-o poisons, for example-passed in to the bile. The effect of "cholagogue" remedies so generally prescribed had been lef $t$ in doubt by experiment. A mixed diet causes a Jarger flow of bile than any drug, and solvent remedies are irrational, since the bile itself is a complete solvent for material contained in it. The excretion of bile must be mechanically aided by improved clothing. The use of salicylic acid \&c. to prevent bacterial infection is not of much service. Since every error in diet brings on attacks, a main indication is strict dieting. The good effect of Carlsbad waters is perhaps due to excitation of peristalsis. Surgical treatment has, owing to the position of the gall-bladder, a fair prospect of good results, and in many cases the gallbladder should be entirely removed. It is usual in practice to regard jaundice as the chief symptom, but very often there is no jaundice present, and the suffering in such cases is often only regarded as gastralgia.

$$
\text { (To bo continued.) }
$$

\section{A BURMESE BUDDHIST AND VACCINATION.}

THE readers of THE LANCES will be interested to hear something of the quiet progress of civilisation in Burmah and measures of Government, apart from punitive expeditions against hill savages and the suppression of dacoits.
The accompanying letter formed part of a correspondence which has lately been published in the vernacular issue of the Government Gazette and widely distributed through the country. It is optional here with municipal boards to make vaccination compulsory within their limits. Since the occurrences herein related several of the larger towns have followed the example of Rangoon and adopted compulsory vaccination. On his return from leave in October last, Dr. Pedley found a letter from the Sanitary Commissioner waiting for a reply. It stated that the President of the Township Committee of Allanmyo had failed in his en. deavours to persuade the people of that place to adopt vaccination, but had heard that the late Chief Commissioner. Sir Charles Bernard, had in Durbar awarded a gold chain to a Loogyee (head man) for furthering the cause of vaccination amongst the Burmese. He inquired by what means the Loogyee had so succeeded.

The following was the reply from Dr. T. F. Pedley, Health Officer, Rangoon Municipality, to the Sanitary Commissioner and Superintendent of Vaccination, Burmah

$$
\begin{aligned}
& \text { Rangoon, Oct. 7th, } 1889 . \\
& \text { No. } \frac{3728}{15 \mathrm{~V}} \text {, dated Aug. }
\end{aligned}
$$

8th, 1889, with enclosures, $I$ have the honour and pleasure to give you an account of the valuable assistance rendered by Oo Dway in furthering the cause of vaccination in Rangoon. Small-pox was prevalent in this municipality in 1883-84. During this epidemic some 2000 people were attacked and 885 died; of these 615 were children. Vaccination was not compulsory -in fact, the Burmese were so prejudiced against the operation that the municipal committee could not decide to have the Act enforced. When the epidemic began the subject of vaccination was much discussed among the Burmese, and a special meeting of the Loogyees was held to consider the matter. I was present, and explained the advantages of the operation, and begged them to assist me in getting the children vaccinated, for many of them were dying in the town. I received many promises, but was greatly discouraged, for very few of the men really ii terested themselves in the matter. When I and the vaccinators visited their quarters they were ready with all sorts of excuses, but did little or nothing to use their influence among their people, so that few children were vaccinated. Oo Dway, Myogan Loogyee (village head man) of Dalla came to me and asked me to pay a visit to his village, which is on the other side of the river, opposite Rangoon. He promised to have a number of children ready, and fixed what he considered would be a fortunate day. I went to Dalla accordingly, and was most agreeably surprised to find that the Loogyee had gathered the women and children, with a large crowd of people, at his house. I was allowed to vaccinate all the babies-Oo Dway's grandehildren first,- which I did with great care and gentleness, promising medicines and special care if any of them should suffer from the operation.

After this, every child in this large village was vacci nated, for Oo Dway persuaded the other Loogyees, and brought me the Sayas (native doctors) and inoculators, whorm we showed how to vaccinale, and convinced them of the efficacy of the operation. This last was not difficult, for it soon became known that, while many children in the adjacent villages were ill or dying of small-pox, in Dalla. there were very few cases, and no deaths from it, among the children. Oo Dway's example had a good effect among the Loogyees in Rangoon, for they began to interest themselves, and many of the Sayas threw aside the old practice of inoculation and learnt how to vaccinate, some of them becoming municipal vaccinators. The prejudices against the operation were broken down; and when the proposal was made to the municipal committee the next year to. enforce vaccination, the Burmese members voted with the Europeans for it. Since then we have had no trouble, and regard the good work of the vaccination department with pride, feeling convinced that large numbers of lives ands much suffering have been saved by its efforts.

One day after the epidemic had ceased, I asked Oo Dway how it was that, while the other Loogyees had disappointed me and given so little assistance in this work, he had come forward. I think his reply is well worthy of record, and his reasons, if widely made known, might do good among his fellow countrymen. He said that he was present at the meeting of Loogyees, and came to the conclusion that if vaccination wonld, as they had been told, save the lives of 
the children, it was a work of great merit, and worthy of the best attention of a good Buddhist. Regarding the matter thus seriously, he made special visits to the Shoay Dagon Pagoda, and in prayer sought the guidance of the higher powers. One night about this time he had a dream. $\mathrm{He}$ thought that while sitting on the bank of the river he saw a number of pieces of wood floating down to the sea. $\mathrm{He}$ thought it a pity that they should thus be wasted. So, getting into a canoe, he paddled out into the stream, and succeeded in collecting a large quantity, which he piled on the shore, and was much pleased with his good luck. He says he thought much about this dream, wondering what it might portend. It dawned upon him that the driftwood meant the lives of the children, which might be saved if he could persuade their parents to have them vaccipated. He hesitated no longer about the matter, but acted as I have above described. I believe Oo Dway to be a kind-hearted man, who lives up to the best teachings of his religion. $\mathrm{He}$ is much beloved by the people of his quarter, and respected by those who know him. I referred to the assistance he had given me in my Sanitary Report for .1884, and mentioned the matter to the Chief Commissioner. Sir Charles Bernard expressed great pleasure in being able to publicly recognise Oo Dway's good work. I know that the reward of the gold chain was not expected, and believe that the highest motives prompted his benevolent endeavours.

I have the honour to be, Sir, your obedient servant, T. F. Pedley,

Health Officer, Rangoon Municipality.

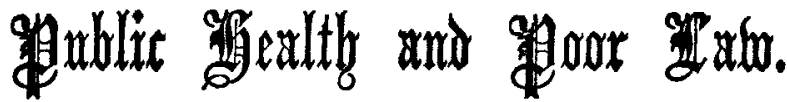

\section{LOCAL GOVERNMENT DEPARTMENT.}

REPORTS OF MEDICAL OFFICERS OF HEALTH.

Teignmouth Urban District. - Dr. Cecil H. Piggott calculates the death-rate during 1890 for the two component parts of this district as 17.2 per 1000 for Teignmouth and i19.3 for Shalden; and, in referring to the infectious diseases, he explains that, the existing means of isolation being inadequate, no cases were removed to the hospital. On the -question of drainage generally, Dr. Piggott reports that the authority has every reason to congratulate itself upon the satisfactory completion of several much-needed improvements. Oddly enough, this same authority, on receiving the report, declared that it tended to convey a "wrong impression to the outside public as to the drainage of the town." We regret to hear this, for if, as Dr. Piggott says, the drainage is now a matter of congratulation, the authority must know something against it which their medical officer of health has not reported on. But this seems hardly possible, and hence we look through the report again to see this meaning of this warning which the local board hes made so public; and the only other explanation of it lies in a detailed account of the sanitary circumstances of a building where enteric fever took place. Happily for Teignmouth, no general faulty condition was found to be -concerned in this preventable disease; it was due to local conditions affecting the actual premises attacked, and Dr. Piggott, drawing the right and proper inference, suggests that action should be taken to prevent any further similar roccurrence. But he adds that in Teignmouth there are, happily, few such spots to be found. And yet this officer is asked for the future so to report as not to prejudice the health of the town. The things that are prejudicial are the high death-rate and the resolution of the authority, and the one comforting fact is a report which explains thai faulty circumstances affecting public sewers and house drainage are not allowed to remain when once discovered. Fortunately, intending visitors to Teignmouth can, so long as the present medical officer of health remains in office, feel assured that improvements called for in the interests of public health will, as heretofore, be continued; and that, if the present high death-rate admits of being speedily reduced, the authority and the public electing them as their representatives, will be openly advised as to the measures that are needed to this end. The authority would do well to pass resolutions which will give confidence to the public, instead of such isuggestive ones as that recently adopted. A resolution, for example, to provide at once some adequate means of isolation would be much more to the benefit of Teignmouth than the attitude now adopted.

Sutton Coldficld Urban District.-The maintained small death-rate, averaging some 12 per 1000 per annum, must be regarded with satisfaction by the Town Council and by Dr. Bostock Hill, their health adviser; and the small zymotic rate adds to the satisfactory result. Where preventable disease occurs, the defects are pointed out and remedied, and this work is made the more complete by the adoption of the Notification Act. The carelessness which goes on in the face of the high mortality from measles in this country is adverted to, and the action which can be taken in con. trolling it by restricting school attendances is pointed out at some length. Excellent records are embodied in the report as to the systematic sanitary action and inspection in progress, and as to the meteorology of the locality; but the year's sanitary history is in one sense satisfactorily brief; for, as Dr. Hill asserts, Sutton Coldfield for three consecutive years has taken its stand in the first rank of healthy towns, and in 1890 it had the lowest rate of general death and of infant death of all the boroughs in the county of Warwick.

Uxbridge Urban District.-Mr. W. Rayner shows the excellent use to which the joint hospital for infectious diseases was put during the past year, and with the steady isolation of diphtheria, which is evidently in progress, we may hope that this disease, which some time since was severely epidemic, may be permanently checked, for inspection of schools and other allied work seems also to be steadily maintained. Happily, only one death from any zymotic disease took place, and where any such cases occurred cleansing, disinfection, isolation, and removal of insanitary circumstances were fully carried out.

Stroud Rural District._-Some detailed account is given by Mr. Partridge as to the general inspection of this district during 1890 and of the results attained, as also of the causes of death which prevailed. The death-rate from all causes has been almost continuously falling since 1875 , and it was 14.7 per 1000 last year ; the zymotic rate was also small-namely, 0.8 per 1000 . Some diphtheria occurred, and, as is commonly the case, it prevailed chiefly amongst children aggregated in one of the elementary schools. Occasion was properly taken to remedy a number of sanitary defects, both at the school and at the houses of those who were attacked. There were also fifty-three attacks from scarlet fever, but no death. Some extension of the public water-service has taken place, but there is need ot similar progress in respect of public sewers.

Stroud Urban District. - Unlike the Stroud rural district, this town is stated to be hesitating about the desirability of learning whether infectious disease is prevailing in its midst or not, and at the date of Mr. Partridge's report notification was still in abeyance. The annual death-rate for 1890 was 16.2 per thousand. Steps are being taken to remedy a deficiency in the public water-supply, and it is to be hoped that when this is completed no further accounts of unwholesome supplies will be possible.

Bisley Urban District.-This district is also under Mr. Partridge's health supervision, and it had a death-rate last year of 15 per thousand living. Some cases resembling enteric fever were found to be associated with defective sanitary surroundings; the water-supply is from wells, many of which are of a doubtful character, and this although a public service would appear to be available. Reading between the lines of this report, it is clear that the health officer is of opinion that the death-rate of this little town is too high, and that there are conditions within it capable at any time of causing much greater mortality.

\section{VITAL STATISTICS.}

\section{HEALTH OF ENGLISH TOWNS.}

IN twenty-eight of the largest English towns 6615 births and 4400 deaths were registered during the week ending April 11th. The annual rate of mortality in these towns, which had been 21.2 and 22.4 per 1000 in the preceding two weeks, further rose to 22.9 last week. The rate was $20^{\circ} 0$ in London and $25 \cdot 3$ in the twenty-seven provincial towns. During the thirteen weeks of last quarter the death-rate in the twenty-eight towns averaged 23.0 per 1000 , and slightly exceeded the mean rate in the corresponding periods of the ten years 1881-90. The lowest rates in these 